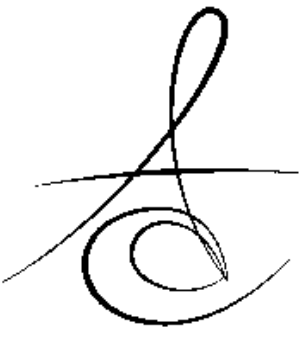

Makale Kodu/Article code: 2688

Makale Gönderilme tarihi: 21.03.2016

Kabul Tarihi: 21.04..2016

\title{
PROTEZ CİLA MATERYALLERİNİN FARKLI KAİDE MADDELERİNİN YÜZEY PÜRÜZLÜLÜĞÜNE ETKİSİ
}

\section{THE EFFECT OF DENTURE POLISH MATERIALS ON THE SURFACE ROUGHNESS OF DIFFERENT BASE MATERIALS}

\author{
Yrd. Doç. Dr. Elif AYDOĞAN AYAZ ${ }^{*} \quad$ Prof. Dr. Bora BAĞIş ${ }^{* *}$ \\ Doc. Dr. Sedanur TURGUT*
}

\section{ÖZET}

Amaç: Protez kaide materyallerinin yüzey pürüzlülüğü protezin klinik kullanımını etkileyen önemli bir özelliktir. Bu çalışmanın amacı farklı cila materyallerinin polimetilmetakrilat (PMMA) ve poliamid içerikli protez kaide maddelerinin, temizleme tableti uygulama sonrası yüzey pürüzlülüğüne etkisinin değerlendirilmesidir. Gereç ve Yöntem: Çalışmada polimetilmetakrilat (QC -20) ve poliamid (Deflex) esaslı iki farklı kaide maddesi kullanılarak toplamda 60 adet örnek $3 \mathrm{~mm}$ kalınlık ve $20 \mathrm{~mm}$ çapta diskler halinde $(\mathrm{n}=10)$ hazırlandı. Kontrol grubunda örnekler pomza ve kıl firça ile cilalandı. İkinci grup örneklere pomza ile yapılan cilayı takiben Universal Polishing Paste, üçüncü gruba ise Palaseal cila materyali uygulandı. Yüzey pürüzlülük ölçümleri örnekler efervesan tablet formundaki Corega temizleyici solüsyon uygulamadan önce ve sonra dijital bir profilometre cihazı kullanılarak yapıldı. Örneklerin pürüzlülük değişiklikleri $(\mathrm{Ra})$ iki yönlü varyans analizi ve Fisher's LSD test ile istatiksel olarak karşılaştırıldı $(p<0,05)$

Bulgular: Cila materyalleri ve protez kaideleri arasında istatiksel olarak anlamlı etkileşimler bulundu $(\mathrm{p}<$ $0,001)$. Cila materyali uygulanan bütün örnekler, sadece pomza ile cilalanan kontrol gruplarına göre daha düşük pürüzlülük değerleri gösterdi $(p<0,001)$. Protez temizleyicisi polimetilmetakrilat ve poliamid rezinlerinin pürüzlülüğünü anlamlı olarak arttırdı $(p<0,001)$

Sonuç: Protez cila materyallerinin uygulanması ile protez yüzeylerinin daha düzgün hale getirilebileceği ve protez temizleyici tabletlerin neden olabileceği yüzey pürüzlülüğünü azaltabileceği göz önünde bulundurulmalıdır.

Anahtar Kelimeler: polimetilmetakrilat; poliamid; protez temizleyicileri; yüzey pürüzlülüğü

\section{ABSTRACT}

Aim: Surface roughness of denture base materials is an important property that affects clinical use of the prostheses. The aim of this study is to evaluate the effect of different polishing materials on surface roughness of polymethlymethacrylate and polyamide denture base resins after use of a denture cleaner.

Material and Method: Total of 60 samples were prepared from polymethlymethacrylate (QC-20) and polyamide (Deflex) as $3 \mathrm{~mm}$ thickness and $20 \mathrm{~mm}$ diameter disc shaped $(n=10)$. Samples were polished with pumice and bristle brush in control groups. Universal Polishing Paste were subjected to the second group after pumice and Palaseal were subjected to the third group. Surface roughness test was performed with a digital prophylometer ( $\mathrm{Ra}$ ) before and after effervesance denture cleaner (Corega). Data were analysed by two way ANOVA and Fischers LSD post hoc test $(p<0,05)$.

Results: Polish materials and denture bases showed significant interactions $(p<0,001)$. Groups polished with polish materials showed significantly lower surface roughness values when compared to control groups that polished only with pumice $(p<0,001)$. Denture cleaner increased the surface roughness of polymethlymethacrylate and polyamide resins significantly $(p<0,001)$.

Conclusion: It should be considered that denture polish materials may provide more smooth denture surfaces and eliminate the deleterious effects of denture cleaners.

Key words: polymethlymethacrylate; polyamide; denture cleaner; surface roughness

\footnotetext{
*Karadeniz Teknik Üniversitesi, Diş Hekimliği Fakültesi, Protetik Diş Tedavisi, AD

** İzmir Katip Çelebi Üniversitesi, Diş Hekimliği Fakültesi, Protetik Diş Tedavisi, AD.

${ }^{\ddagger}$ Bu çalışma 18-20 Mart 2016 tarihlerinde 5. Uluslararası TPID Palandöken Kış Sempozyumunda poster bildiri olarak sunulmuştur
} 


\section{GİRİ̧̧}

Polimetilmetakrilat (PMMA) protez kaide materyali olarak aranan özellikleri karşılayabilmesi sebebiyle hareketli protezlerin yapımında yaygın olarak kullanılmaktadır. Ağız içerisindeki çiğneme kuvvetlerine yeterli direnci, sıvılarda düşük çözünürlük özelliği, uygulama ve tamir işlemlerinin kolay olması gibi önemli avantajlara sahiptir. ${ }^{1}$ Bunun yanında polimerizasyon büzülmesi, çarpma dayanıklılı̆ı ve yorulma direncinin düşük olması ile bazı hastalarda alerjik reaksiyonlara sebep olabilmesi alternatif bir kaide materyali arayışına yol açmıştır. ${ }^{2}$ Naylon olarak da bilinen poliamid, diamin ve dibazik asitin reaksiyona girmesi ile oluşan termoplastik bir polimerdir. Esneyebilir olması, düşük özgül ağırlığı, darbelere karşı dayanıkıı̆ı̆ı, sitotoksik etkisinin olmaması poliamidin kaide materyali olarak kullanılmaya başlanmasına olanak sağlamıştır. 2,3 Artık monomer içermemesi özellikle akrilik rezine alerjisi olan hastalarda tercih edilmesine sebep olmuştur. ${ }^{4}$

Ağız içerisinde yaşayan çok sayıda mikroorganizma olmasına rağmen; bu mikroorganizmaların çürük, periodontal hastalık ya da protez stomatitine neden olabilmeleri için ağız içerisinde tutunup kolonizasyon oluşturmaya başlamaları gerekmektedir. ${ }^{5} \mathrm{Bu}$ oluşumda yüzey pürüzlülüğü ve serbest yüzey enerjisi anahtar rol oynamaktadır. Tükrük pelikılın rezin yüzeylerde oluşturduğu biofilm tabakası dental materyallerin serbest yüzey enerjisini etkilemektedir. Pürüzlü akrilik rezin yüzeylerin, bakteri akümülasyonu ve plak formasyonu açısından az pürüzlü düzgün yüzeylere oranla anlamlı olarak farklılık gösterdiğini bildiren çalışmalar mevcuttur. ${ }^{6,7} \mathrm{Bu}$ faktörler göz önünde bulundurulduğunda dental materyallerin bitim ve polisaj işlemleri klinik açıdan önem kazanmaktadır. Hareketli protezlerin cila işlemleri, dental teknisyenler tarafından laboratuarlarda, genellikle pomza ve çeşitli şekillerdeki kıl, keçe ve pamuk firçalarla tamamlanmaktadır. ${ }^{8}$ Plak oluşumu ve renklenmenin kontrol altına alınabilmesi amacıyla protezlerin konvansiyonel bitim işlemlerini takiben alüminyum oksit partikülleri içeren cila pastaları veya ışınla sertleşen protez cilaları da polisaj işlemlerinde kullanılmaktadır. ${ }^{9,10}$ Böylece akrilik rezin protezlerin yüzeylerinin daha düzgün hale getirilmesi amaçlanmaktadır. Bu materyallerin uygulanması ile yüzeydeki defektlerin doldurulduğu ve pürüzsüz yüzeylerin oluştuğu bildirilmektedir. ${ }^{11} \quad$ Ayrıca uygulandıkları yüzeyi, aşınma ve renklenmeye karşı dirençli hale getirdikleri rapor edilmiştir. ${ }^{12,13}$

Protez temizleyicilerinin kullanımı, plak oluşumunu kontrol etmek ve Candida Albicans kolonizasyonunu önlemek amacıyla kısa veya uzun süreli olarak önerilebilir. Protez temizliğinde sıklıkla kullanılan alkalen hipoklorit/sodyum perborat içerikli, efervesan tipi temizleyicilerin protez yüzeyinde oluşan organik matriksi eriterek plak oluşumunu inhibe ettikleri bildirilmiştir. ${ }^{14}$ De Freitas Fernandes ve ark., ${ }^{15}$ poliamid kaide materyalleri üzerinde protez temizleyicilerinin etkinliğini değerlendirmek amacıyla, PMMA ve poliamid rezinleri enzimatik yapıdaki Polident ve Corega solüsyonunda bekleterek yaptıkları çalışmanın sonucunda, solüsyonların tüm rezin örneklerdeki bakteri suşları üzerinde yüksek etkinlik gösterdiğini bildirilmişlerdir. Temizleyici solüsyonların aralıklı veya uzun süreli kullanımına bağlı olarak yüzey pürüzlülüğü, renk ve parlaklık gibi yüzey özelliklerinin etkilendiğini rapor eden çok sayıda çalışma mevcuttur. ${ }^{4,16,17}$

PMMA ve poliamid kaide materyallerinin değişik solüsyonlardaki yüzey pürüzlülüğü ile protez temizleyicilerinin bu kaide materyallerinin yüzey özelliklerine etkilerini inceleyen çalışmalar olmasına rağmen, farklı cila materyallerini ve bunlar uygulandıktan sonra protez temizleyicilerinin etkisini inceleyen herhangi bir çalışmaya rastlanamamıştır. Bu çalışmanın birinci amacı, farklı cila materyalleri kullanılarak bitirilen PMMA ve poliamid kaide materyallerinin yüzey pürüzlülüğünün değerlendirilmesidir. Çalışmanın ikinci amacı ise, farklı cila materyalleri kullanılarak bitirilen kaide materyallerinin alkalen hipoklorit esaslı protez temizleyicisi sonrası yüzey pürüzlülüğünün değerlendirilmesidir. Çalışmanın sıfır hipotezi, farklı protez cilaları ve alkalen peroksit içerikli protez temizleyicisinin PMMA ve poliamid yapıdaki protez kaide materyallerinin yüzey pürüzlülük değerlerini değiştirmeyeceğidir.

\section{GEREÇ VE YÖNTEM}

Çalışmada protez kaide materyali olarak ISı ile polimerize olan akrilik rezin (QC-20) ve enjeksiyon yöntemiyle polimerize edilen poliamid (Deflex) kullanıldı (Tablo 1). Örneklerin hazırlanması için $3 \mathrm{~mm}$ kalınlık ve 20 mm çapında metal kalıpta 60 adet mum

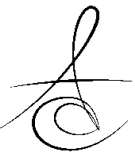


Tablo 1. Çalışmada kullanılan materyaller

\begin{tabular}{|l|l|l|}
\hline Materyaller & Üretici firma & İçerik \\
\hline QC-20 & $\begin{array}{l}\text { Dentsply Ltd, } \\
\text { Addlestone, } \\
\text { UK }\end{array}$ & Polimetilmetakrilat \\
\hline Deflex & $\begin{array}{l}\text { Nuxen SRL, } \\
\text { Buenos Aires, } \\
\text { Arjantin }\end{array}$ & Poliamid/nylon \\
\hline $\begin{array}{l}\text { Universal } \\
\text { polising } \\
\text { paste }\end{array}$ & $\begin{array}{l}\text { Ivoclar } \\
\text { Vivadent, } \\
\text { Schaan, } \\
\text { Liechtenstein }\end{array}$ & Alüminyum oksit partikül $\left(\mathrm{Al}_{2} \mathrm{O}_{3}\right)$ \\
\hline Palaseal & $\begin{array}{l}\text { Heraeus } \\
\text { Kulzer GmbH, } \\
\text { Hanau, } \\
\text { Almanya }\end{array}$ & $\begin{array}{l}\text { Methyl methacrylate, tris(2- } \\
\text { hydroxyethyl)-isocyanurate- } \\
\text { triacrylate, } \\
\text { acrylizedepoxyoligomer, } \\
\text { acrylates, acrylizedpolysiloxane }\end{array}$ \\
\hline Corega & $\begin{array}{l}\text { Block Drug } \\
\text { Company, } \\
\text { Inc., } \\
\text { Jersey City, } \\
\text { New Jersey- } \\
\text { NJ, Amerika }\end{array}$ & $\begin{array}{l}\text { Potassium } \\
\text { Sodium Bicarbonate; Sodium } \\
\text { Lauryl Sulfoacetate; Sodium } \\
\text { Perborate Monohydrate; Sodium } \\
\text { Polyphosphate }\end{array}$ \\
\hline \multicolumn{2}{|l}{} \\
\hline
\end{tabular}

örnek şekillendirildi. Isı ile polimerize olan akrilik rezinler $100^{\circ} \mathrm{C}$ de sıcak suda 30 dakika kaynatılarak polimerize edildi. Poliamid rezinler üretici firmanın önerileri doğrultusunda $270-288^{\circ} \mathrm{C}$ de 11 dakika eritilerek 6 bar basınç altında 30 saniyede mufla içerisine enjekte edildi. Polimerizasyonun ardından tüm örnekler kendi kendine soğumaya bırakıldı. Elde edilen örneklerin işlem yapılacak yüzeyleri otomatik cilalama makinesi ile 200-800 grenli karbid zımpara kullanılarak (Grin PO 2 V grinderpolisher, Metkon A.S., Bursa, Türkiye) cilalandı. Tesviye işlemleri tamamlanan örnekler pomza/su karışımı ve kıl fırça ile cilalandı. Ardından her rezin grubundan 10'ar adet örnek $(n=10)$ seçilerek üçer adet alt gruba ayrıldı. İlk grup hiçbir uygulama yapılmadan bırakıldı ve kontrol grubu olarak adlandırıldı. İkinci grup örneklerin yüzeyine, sulu pomzanın ardından, Universal Polishing Paste cila pastası kıl fırça ile sürüldü. Üçüncü grup örneklerin yüzeyine ise sulu pomzayı takiben Palaseal cilası üretici firmanın önerilerine göre ince uçlu fırça kullanılarak sürüldü. 20 saniye bekledikten sonra 90 saniye ışın uygulandı.

Cila işlemleri tamamlanan örnekler 24 saat süreyle $37^{\circ} \mathrm{C}$ sıcaklıktaki distile suda bekletildi ve yüzey pürüzlülüğü ölçümleri yapıldı. Yüzey pürüzlülük (Ra) ölçümleri dijital bir profilometre cihazında (SJ201P; Mitutoya Corp, Kawasaki, Japonya) 0,4 gram yük ile 5 saniye süreyle $0.01 \mu \mathrm{m}$ çözünürlükte gerçekleştirildi. Ölçümler örnek yüzeylerinin üç farklı alanında tekrarlandı ve değerlerin ortalaması alınarak her bir örneğin yüzey pürüzlülüğü hesaplandı. Protez temizleyici tablet üretici firmanın önerileri doğrultusunda ılık suda çözülerek 15 dakikalık standart sürede örneklere uygulandı. Ardından örnekler akan su altında yıkandı ve distile suda saklandı. Bu uygulama 30 gün boyunca taze olarak hazırlanan solüsyonda tekrarlandı ve 30 gün sonunda yüzey pürüzlülük ölçümleri tekrarlandı.

\section{İstatiksel Analiz}

Verilerin normal dağılıma uygunluğu Shapiro wilk testi ile değerlendirildi (SPSS, version 16.0, SPSS, Chicago, IL, USA). Farklı cila materyallerinin farklı kaide maddeleri üzerine etkisinin değerlendirilmesi için iki yönlü varyans analizi (ANOVA) testi ve Fisher's LSD test uygulandı. Protez temizleyicinin pürüzlülüğe etkisinin değerlendirilmesi için paired sample t-test uygulandı. Tüm karşılaştırmalar \%95 güven aralığında gerçekleştirildi $(p<0,05)$.

\section{BULGULAR}

İki yönlü varyans analizi sonuçlarına göre kaide ve cila materyalleri arasında anlamlı bir etkileşim olduğu görüldü $(p<0,001)$ (Tablo 2$)$. Kaide materyallerinin temizleyici solüsyon uygulamadan önceki ve sonraki yüzey pürüzlülüğü ortalama değerleri ve standart sapmaları Tablo 3'de gösterildi. Bütün cila uygulamalarında, PMMA ve poliamid rezinler arasında Ra değerleri açısından anlamlı farkılık görüldü $(p<0,001)$. Poliamid materyali her durumda pmma materyali ile karşılaştırıldığında daha yüksek pürüzlülük değerleri gösterdi $(p<0,001)$. Polishing Paste ve Palaseal uygulanan ikinci ve üçüncü grup PMMA ve poliamid Ra değerleri, yalnızca pomza ile bitirilen kontrol grubu örneklerle karşılaştırıldığında anlamlı olarak düşük bulundu $(p<0,001)$. Her iki kaide materyaline Corega uygulaması $\mathrm{Ra}$ ortalama değerlerini anlamlı olarak arttırdı $(p<0,001)$. Corega sonrasında en yüksek pürüzlülük değerleri pomza ile bitirilen gruplarda görüldü $(p<0,001)$. Corega ile temizleme öncesinde poliamid grubunun Polishing Paste ve Palaseal alt grupları arasında ve Corega sonrasında PMMA grubunun Polishing Paste ve Palaseal alt grupları arasında fark görülmedi ( $p>0,001)$. 
Tablo 2. İki yönlü Varyans analizi testi sonuçları

\begin{tabular}{|c|c|c|c|c|c|c|}
\hline & SS & df & MS & $\mathrm{F}$ & $P$ & \\
\hline $\begin{array}{c}\text { Kaide } \\
\text { materyali }\end{array}$ & 0,072 & 1 & 0,072 & $\begin{array}{c}833,38 \\
7\end{array}$ & 0,000 & \multirow{3}{*}{$\begin{array}{l}\text { Corega } \\
\text { öncesi }\end{array}$} \\
\hline $\begin{array}{c}\text { Cila } \\
\text { materyalleri }\end{array}$ & 0,029 & 2 & $\begin{array}{c}0, \\
014\end{array}$ & $\begin{array}{c}165,26 \\
5\end{array}$ & 0,000 & \\
\hline $\begin{array}{l}\text { Kaide } x \text { Cila } \\
\text { materyalleri }\end{array}$ & 0,002 & 2 & 0,001 & 11,305 & 0,000 & \\
\hline $\begin{array}{c}\text { Kaide } \\
\text { materyali }\end{array}$ & 0,045 & 1 & 0,045 & $\begin{array}{c}405,85 \\
6\end{array}$ & 0,000 & \multirow{3}{*}{$\begin{array}{l}\text { Corega } \\
\text { sonrası }\end{array}$} \\
\hline $\begin{array}{c}\text { Cila } \\
\text { materyalleri }\end{array}$ & 0,085 & 2 & 0,043 & $\begin{array}{c}383,18 \\
8 \\
\end{array}$ & 0,000 & \\
\hline $\begin{array}{l}\text { Kaide } x \text { Cila } \\
\text { materyalleri }\end{array}$ & 0,017 & 2 & 0,008 & 76,247 & 0,000 & \\
\hline
\end{tabular}

Tablo 3. Kaide materyallerinin yüzey pürüzlülük ortalama değerleri ve standart sapmaları $(\mathrm{Ra} / \mu \mathrm{m})$

\begin{tabular}{|c|c|c|c|c|}
\hline Cila materyali & \multicolumn{2}{|c|}{ Corega öncesi } & \multicolumn{2}{|c|}{ Corega sonrası } \\
\hline $\begin{array}{c}\text { Kaide } \\
\text { materyalleri }\end{array}$ & PMMA & POLİAMID & PMMA & POLİAMID \\
\hline Pomza (P) & $0,11 \pm 0,01 \mathrm{aA}$ & $0,19 \pm 0,01 \mathrm{aC}$ & $0,29 \pm 0,01 \mathrm{aB}$ & $0,29 \pm 0,01 \mathrm{aD}$ \\
\hline $\begin{array}{c}\text { Polishing paste } \\
\text { (PP) }\end{array}$ & $0,09 \pm 0,01 \mathrm{bA}$ & $0,15 \pm 0,02 \mathrm{bC}$ & $0,18 \pm 0,01 \mathrm{bB}$ & $0,27 \pm 0,01 \mathrm{bD}$ \\
\hline Palaseal (PS) & $0,06 \pm 0,02 \mathrm{cA}$ & $0,13 \pm 0,01 \mathrm{bC}$ & $0,17 \pm 0,01 \mathrm{bB}$ & $0,24 \pm 0,01 \mathrm{cD}$ \\
\hline
\end{tabular}

Aynı sütundaki farklı küçük harfler kaide materyallerinin grup içi farklılıklarını göstermektedir $(p<0,05)$

Aynı satırdaki farklı büyük harfler kaide materyallerinin Corega uygulamasına bağı farklılıkları göstermektedir $(p<0,05)$

\section{TARTIŞMA}

Mevcut çalışma sonuçlarına göre çalışmanın sıfır hipotezi reddedilmiştir. PMMA ve poliamid kaide materyallerine uygulanan farklı cila materyalleri ve kaide materyallerin Corega ile temizlenmesi yüzey pürüzlülük değerlerini anlamlı olarak değiştirmiştir.

Protezlerin hastaya tesliminden önce pürüzlerin giderilmesi, düzgün ve parlak bir yüzey elde edilmesi amacıyla bitim ve cila işlemleri yapılmaktadır. Bu işlem yüzeyin düzleştirilmesi ve parlatılması demektir. Protezlerin cilalanması ile canlı dokuların tahriş olmaması, kaide materyalinin ise aşınma ve renklenmeye karşı direnç kazanması sağlanır. Cila işlemleri çeşitli şekillerdeki pamuk, kıl, keçe fırçalar kullanılarak; pomza ve su karışımı ile dental laboratuarlarda yapılmaktadır. ${ }^{10}$ Bunların yanında çeşitli cila pastaları ya da silikon frezler içeren parlatma setlerinin uygulanması ile yüzeyin düzgünleştiğini bildiren çalışmalar mevcuttur. Kuhar ve Funduk ${ }^{11}$, silikon parlatma diskleri ve alüminyum oksit içerikli polisaj pastası uyguladıkları akrilik rezinlerin daha az pürüzlü yüzeylere sahip olduklarını bildirmişlerdir. Şen ve ark. ${ }^{18}$ akrilik ve kompozit rezinlerin alüminyum oksit içerikli cila pastaları ile yüzeylerinin düzgünleştiğini ve bu etkinin partiküllerin yüzeydeki düzensizlikleri elimine etmesi yoluyla sağlanmış olabileceğini bildirmişlerdir. Önceki çalışmalara benzer şekilde, bu çalışmada da her iki kaide materyalinin Polishing Paste ve Palaseal uygulanan gruplarında yüzey pürüzlülük değerleri anlamlı olarak azalmıştır. Palaseal, yapısındaki metil metakrilat molekülleri, protez kaide materyallerinin yüzeyine yapışarak yüzeydeki mikrodefektlerin doldurulmasını sağlar. Ayrıca materyalin yapısındaki bu moleküller kaide rezini polimer yapısına katılarak yüzeyin modifiye edilmesine etki etmiş olabilir. Sesma ve ark. ${ }^{19}$ cila materyallerinin protez yüzeyindeki plak formasyonuna etkinliğini değerlendirdikleri in vivo çalışmalarında, Palaseal uygulanan protezlerin taramalı elektron mikroskop görüntülerinin, Palaseal uygulanmayanlara göre daha düzgün olduğunu bildirmişlerdir.

Hareketli protezlerin hastaya teslimi sırasında veya sonrasında yapılan aşındırmalara bağı olarak açığa çıkan pürüzlü yüzeylerin düzenlenmesi amacıyla da cila pastaları veya silikon cila kitleri kullanılmaktadır. Bu materyaller, protezin cilalanması için tekrar dental laboratuvara gönderilmeden, hasta başında uygulama kolaylığı sağlaması avantajına sahiptir. Chatzivasileiou ve ark. ${ }^{20}$ hasta başında kullanılan cila setlerinin etkinliğini değerlendirmek amacıyla, ISI ile polimerize olan akrilik rezinleri farklı tekniklerle cilalamış ve yüzey pürüzlülük değerlerini karşılaştırmışlardır. Çalışma sonuçlarına göre en düşük pürüzlülük değerlerinin laboratuarda cilalanan gruplarda görülmesine rağmen, hasta başında uygulanan cila işlemlerinin de gerekli durumlarda alternatif olarak kulanılabileceğini bildirmişlerdir. Güngör ve ark. ${ }^{21}$ ise ISı ile polimerize, otopolimerize akrilik ve poliamid rezinleri; konvansiyonel olarak laboratuarda veya hasta başı cila kitleri ile cilalamış ve en düşük pürüzlülük değerlerinin konvansiyonel olarak cilalanan gruplarda görüldüğünü rapor etmişlerdir. Rahal ve ark. ${ }^{22}$ akrilik rezinlerin cila işlemlerinde mekanik ve kimyasal yöntemi karşılaştırmış ve sonuç olarak cila materyallerinin kullanıldığı kimyasal yöntem ile bitirilen örneklerin daha düşük pürüzlülük değerlerine sahip olduğunu bildirmişlerdir.

Mevcut çalışmada, PMMA ve poliamid rezinlerin sadece sulu pomza ile bitirilen kontrol grupları diğer gruplardan anlamlı olarak farklı iken, Corega ile temizleme öncesinde PMMA grubunun Polishing Paste

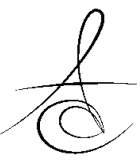


ve Palaseal alt grupları arasında ve Corega sonrasında poliamid grubunun Polishing Paste ve Palaseal alt grupları arasında da kendi aralarında fark görülmüştür. $\mathrm{Bu}$ farklı̆ı̆ın sebebi kaide ve cila materyallerinin değişik kompozisyon ve polimerizasyon şekilleri ile açıklanabilir.

Şahin ve ark. ${ }^{23}$, PMMA ve kompozit rezin esaslı yapay dişlere farklı cila teknikleri ve termal siklus uygulayarak yüzey pürüzlülüğü ve renk stabilitelerini değerlendirdikleri çalışmalarında, Palaseal ile cilalanan grupların konvansiyonel pomza ile cilalama yapılan gruplarla karşılaştırıldığında daha pürüzsüz ve renklenmeye dirençli olduğunu bildirmişlerdir. Bu çalışma bulguları, bizim bulgularımızla paralellik göstermektedir.

Dental materyaller için kritik yüzey pürüzlülüğü değeri olarak $\mathrm{Ra}=0.2 \mu \mathrm{m}$ belirlenmiş ve bu değerin üzerindeki pürüzlü yüzeylerde plak akümülasyonunda hızlı artış olduğu bildirilmiştir. ${ }^{5}$ Çalışmamızda PMMA ve poliamid rezinlerin ortalama Ra değerleri, Corega uygulamasından önce, belirlenen sınırın altında ölçüldü. Corega uygulandıktan sonra PMMA rezinlerin pürüzlülük değerleri $0.2 \mu \mathrm{m}$ sınııını aşmazken, poliamid rezinlerin pürüzlülükleri ise tüm gruplarda bu sınırın üzerinde bulundu. Bu çalışmanın sonuçlarına göre, klinik uygulamalar sırasında, kaide materyali seçerken poliamid materyalinin poröz yapısı göz önünde bulundurulmalıdır.

Çalışmamızda Corega temizleme tabletleri ile pürüzlülük değerleri bütün örneklerde anlamlı olarak arttı. Efervesan tablet suda çözündüğünde, sodyum bikarbonat ayrışarak serbest radikaller içeren alkali peroksit solüsyonu oluşturur. Bu peroksit solüsyonu da oksijen salınımı yaparak eklentileri mikromekanik olarak uzaklaştırma yoluyla etki gösterir. ${ }^{24,25}$ Yüksek peroksit içeriği ve güçlü bir alkali solüsyon içindeki oksijenasyon seviyesinin, protez kaide materyallerine zarar veren bir faktör olduğu belirtilmiştir. ${ }^{25,26}$ Çalışmada kullanılan Corega protez temizleyicisi alkali peroksit, sodyum perborat ve sodyum karbonat içerikli suda çözünen efervesan tablet formundadır. Kaide materyallerinin yüzey pürüzlülüğü değerlerindeki artış, temizleme işlemi sırasında açı̆̆a çıkan serbest radikallerin mekanik etki göstererek materyallerinin yüzeyini değiştirmesi ile açıklanabilir. Bu çalışma sonuçlarına benzer şekilde, Durkan ve ark. ${ }^{16}$ PMMA ve poliamid içerikli kaide materyallerini Corega, Protefix ve Valclean temizleyici solüsyonlarda bekletmiş ve 20 günün sonunda materyallerin yüzey pürüzlülük değerlerinde artış olduğunu bildirmiştir.

Çalışmada kullanılan örneklerin düz yüzeyli olması, ağız içinde kullanılan protezin yüzey yapısını tam olarak taklit edememesi ve ortamda tükrük tabakasının olmaması mevcut çalışmanın limitasyonları olarak sayılabilir. Kaide materyallerinin yüzeylerine uygulanan polisaj maddelerinin yapay diş materyallerinin fiziksel özelliklerine etkisi de araştırıması gereken konulardandır.

\section{SONUC}

Bu çalışmanın sınırları dahilinde, protez cila materyallerinin uygulanması ile protez yüzeylerinin daha düzgün hale getirilebileceği ve protez temizleyici tabletlerin neden olduğu yüzey pürüzlülüğünü azaltabileceği göz önünde bulundurulmalıdır. Bu nedenle, protezlerin hastaya tesliminden önce çeşitli cila materyallerinin uygulanması önerilebilir.

\section{KAYNAKLAR}

1. O Brian WJ. Dental Material and their selection. 4 ed. Chicago; Quintessence Publishing: 2008. p. 75-113.

2. Uçar Y, Bakar O, Ekinci M, Kayar B. Poliamid ile farklı polimetilmetakrilat protez kaide materyallerinin mikroorganizma tutulumunun karşılaştırıması. S.D.Ü. Tıp Fak. Derg 2013;20:8-13.

3. Yunus N, Rashid AA, Azmi LL, Abu-Hassan MI. Some flexural properties of a nylon denture base polymer. J Oral Rehabil 2005;32:65-71.

4. Polychronakis NC, Polyzois GL, Lagouvardos PE, Papadopoulos TD. Effects of cleansing methods on 3-D surface roughness, gloss and color of a polyamide denture base material. Acta Odontol Scand 2015;73:353-63.

5. Bollen CM, Lambrechts P, Quirynen M. Comparison of surface roughness of oral hard materials to the threshold surface roughness for bacterial plaque retention: a review of the literature. Dent Mater 1997; 13:258-69.

6. Sipahi C, Anıl N, Bayramlı E. The effect of acquired salivary pellicle on the surface free energy and wettability of different denture base materials. J Dent 2001;29:197-204.

7.Morgan TD, Wilson M. The effects of surface roughness and type of denture acrylic on biofilm formation by Stretococcus oralis in constant depth

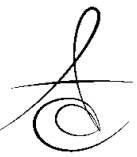


film fermentor. J Appl Microbiol 2001;91:47-53.

8.Sofou A, Emmanouil J, Peutzfeldt A, Owall B. The effect of different polishing techniques on the surface roughness of acrylic resin materials. Eur J Prosthodont Restor Dent 2001;9:117-22.

9.O'Donnel EF, Radford DR, Sinclair GF, Clark RK. Chairside polishing of heat-cured acrylic resin: an SEM and EDA study. Int J Prosthodont 2003; 16:233-8.

10. Ulusoy M, Ulusoy N, Aydın AK. An evaluation of polishing techniques on surface roughness of acrylic resins. J Prosthet Dent 1986;56:107-12.

11. Kuhar M, Funduk N. Effects of polishing techniques on the surface roughness of acrylic denture base resins. J Prosthet Dent 2005;93:76-85.

12.Bertrand MF, Leforestier $E$, Muller M, Lupi-Pégurier $L$, Bolla M. Effect of surface penetrating sealant on surface texture and microhardness of composite resins. J Biomed Mater Res 2000;53:658-63.

13. Doray PG, Eldiwany MS, Powers JM. Effect of resin surface sealers on improvement of stain resistance for a composite provisional material. J Esthet Restor Dent 2003;15: 244-50.

14.Akşit KS, Nakipoğlu Y, Günel G, Mandalı G, Gürler B. Diş protez temizlik ürünlerinin bakteriyolojik aktivitelerinin araştıııması. Atatürk Üniv Diş Hek Fak Derg 2015;25:47-53.

15. De Freitas Fernandes FS, Pereira-Cenci T, Da Silva WJ, Filho AP, Straioto FG, Del Bel Cury AA. Efficacy of denture cleansers on Candida spp. biofilm formed on polyamide and polymethyl methacrylate resins. J Prosthet Dent 2011;105:51-8.

16. Durkan R, Ayaz EA, Bagis B, Gürbüz A, Öztürk N, Korkmaz FM. Comparative effects of denture cleansers on physical properties of polyamide and polymethyl methacrylate base polymers. Dent Mater J 2013;32:367-75.

17. Panariello $B H$, Izumida $F E$, Moffa EB, Pavarina AC, Jorge $\mathrm{JH}$, Giampaolo ET. Effects of short-term immersion and brushing with different denture cleansers on the roughness, hardness, and color of two types of acrylic resin. Am J Dent 2015;28:150-6.

18.Şen D, Göller $G$, İşsever $H$. The effect of two polishing pastes on the surface roughness of bisacryl composite and methacrylate-based resins. J Prosthet Dent 2002;88:527-32.
19. Sesma N, Lagana DC, Morimoto S, Gil C. Effect of denture surface glazing on denture plaque formation. $\mathrm{Br}$ Dent J 2015 dx.doi.org/10. 1590/S0103-64402005000200008

20. Chatzivasileiou K, Emmanouil I, Kotsiomiti E, Pissiotis A. Polishing of Denture Base Acrylic Resin with Chairside Polishing Kits: An SEM and Surface Roughness Study. Int J Prosthodont 2013;26:7981.

21. Güngör $H$, Gündoğdu $M$, Yeşil Duymuş $Z$. Investigation of the effect of different polishing techniques on the surface roughness of denture base and repair materials. J Prosthet Dent 2014;112:1271-7.

22. Rahal JS, Mesquita MF, Henriques GEP, Nóbilo MAA. Surface roughness of acrylic resins submitted to mechanical and chemical polishing. J Oral Rehabil 2004;31:1075-79.

23.Şahin O, Dede DÖ, Köroğlu A, Yılmaz B. Influence of surface sealant agents on the surface roughness and color stability of artificial teeth. J Prosthet Dent 2015;114:130-7.

24.Nikawa $H$, Iwanaga $H$, Hamada $T$, Yuhta S. Effects of denture cleansers on direct soft denture lining materials. J Prosthet Dent 1994;72:657-62.

25. Nikawa $\mathrm{H}$, Hamada T, Yamashiro $\mathrm{H}$, Kumagai $\mathrm{H}$. A review of in vitro and in vivo methods to evaluate the efficacy of denture cleansers. Int J Prosthodont 1999;12:153-9.

26. Kurtulmuş-Yılmaz S, Ozan O, Ramoğlu S, Aktöre $H$, Hamiş A. Protez temizleyicilerinin yumuşak astar maddelerinin renk stabiliteleri üzerine etkisinin değerlendirilmesi. Atatürk Üniv Diş Hek Fak Derg 2015;25:59-65.

\author{
Yazışma Adresi \\ Yrd. Doç. Dr. Elif AYDOĞAN AYAZ \\ Karadeniz Teknik Üniversitesi, \\ Diş Hekimliği Fakültesi, \\ Protetik Diş Tedavisi \\ Telephone: +90 5333108966 \\ Fax: +90 4623414758 \\ E-mail: aydelif@yahoo.com
}

